\title{
THE RELATIONSHIP INVESTIGATION BETWEEN BITCOIN AND SAFE INVESTMENT PRODUCTS (HAVENS) BY THE MARKOW REGIME SWITCHING MODEL AFTER TRADE WARS
}

\author{
DOI: 10.17261/Pressacademia.2020.1181 \\ JEFA- V.7-ISS.1-2020(6)-p.54-65
}

\section{Cuneyt Dirican}

Istanbul Arel University, Department of Accounting and Finance, Tepekent, Buyukcekmece, Istanbul, Turkey. cuneytdirican@arel.edu.tr, ORCID: 0000-0001-6622-3926

\begin{tabular}{l}
\hline Date Received: January 15, $2020 \quad$ Date Accepted: March 23,2020 \\
\hline To cite this document \\
Dirican, C. (2020). The relationship investigation between Bitcoin and safe investment products (havens) by the Markow Regime Switching \\
Model after trade wars. Journal of Economics, Finance and Accounting (JEFA), V.7(1), p.54-65. \\
Permemant link to this document: $\frac{\text { http://doi.org/10.17261/Pressacademia.2020.1181 }}{\text { Copyright: Published by PressAcademia and limited licenced re-use rights only. }}$
\end{tabular}

\section{ABSTRACT}

Purpose- Determination whether there exists a connection or interaction between Bitcoin and safe investment products, which were seen as safe havens, during the trade wars formalized with US President Donald Trump after the 2016 US presidential election is the main of this paper. With the first tariff raise (application) which officially started trade wars, it is desired to understand whether there was a change in the safe investment product preference in the period of the first tariff raise and the US Central Bank's decision to enlarge the balance sheet over the NY FED in September 2019 (after the July 2019 first interest rate cut) due to the liquidity shortage between banks.

Methodology-Using Markow Regime Switching Model, the relationship between Bitcoin, gold, silver, Swiss franc and Japanese yen between these two dates and market regimes (bullish, bearish) were examined. Since the dollar and the euro have already been seen as safe havens as base currency, they are not included in the analysis.

Findings- If bullish, Japanese yen and Swiss franc can affect investors in Bitcoin's investment decisions, contrary it can be seen that there is not any effect in the bear market regime. In Bitcoin, investor behavior is longer to hold its position in the bear market.

Conclusion- Similar to some studies in the literature, during the period of trade wars, Bitcoin could be evaluated as a profit-making investment instrument and portfolio diversification rather than being a safe investment product (haven) among the regimes.
\end{abstract}

Keywords: Investment Banking, Cryptocurrencies, Gold, Foreign Exchange, Forex, Financial Markets

JEL Codes: E44, F31, G11, G24, O16

\section{TICARET SAVAŞLARI SONRASINDA BITCOIN VE GÜVENLI YATIRIM ÜRÜNLERI (LIMANLARI) ARASINDAKI ILIŞKININ MARKOW REJIM DEĞiŞiM MODELi iLE INCELENMESi}

\section{ÖZET}

Amaç - Bu çalışmanın amacı, 2016 ABD başkanlık seçimi sonrası ABD Başkanı Donald Trump'ın kararı ile uygulamaya geçen ilk gümrük tarife artışı ile resmiyete dökülen ticaret savaşları döneminde, Bitcoin ile güvenli liman olarak görülen yatırım ürünleri arasında bir bağlantı, etkileşim olup olmadığının tespit edilmesidir. İlk gümrük tarife uygulaması ile ABD Merkez Bankası'nın bankalar arasındaki likidite sıkışıklığı nedeni ile (Temmuz 2019 ilk faiz indirimi sonrasında) Eylül 2019'da NY FED üzerinden bilanço büyütme kararı almasına kadar geçen aradaki dönemde güvenli yatırım ürünü tercihinde bir değişiklik olup olmadığı hususu bu çalışmanın amacıdır.

Metodoloji- Markow Rejim Değişim Modeli ile bu iki tarih ve rejimler (boğa, ayı piyasası) arasındaki Bitcoin, altın, gümüş, İsviçre frangı ve Japon yeni ilişkisine bakılmıştır. Dolar ve Euro baz para olarak zaten güvenli liman olduğundan ayrıca analize dahil edilmemiştir.

Bulgular- Boğa piyasasında Yen ve Frangın Bitcoin'de yatırımcıya etki edebileceği, ayı piyasası rejimindeyse Bitcoin adına bir etkinin görülmediği söylenebilir. Bitcoin özelinde ayı piyasasında yatırımcı davranışı daha uzun pozisyon tutma şeklinde olmaktadır.

Sonuç- Ticaret savaşları döneminde, literatürdeki bazı benzer çalışmaların sonucuna uygun şekilde, dalgalanma dönemlerinde rejimler arasında Bitcoin güvenli yatırım ürünü (limanı) olmaktan çok getiri amaçlı ve portföy çeşitlendirme ürünü olarak değerlendirilebilecektir.

Keywords: Yatırım bankacılığı, kripto paralar, altın, döviz, foreks, finansal piyasalar.

JEL Kodları: E44, F31, G11, G24, O16 


\section{GiRiş}

Küresel finansal piyasalarda yatırımcı davranışları birçok siyasi, teknolojik, doğa, göç, ekonomik gelişmeden etkilenmektedir. 1990 'I yılların sonunda başlayan ve hızlanan web ve mobil teknoloji tabanlı gelişmelerin yarattığı dijital ekonomi, finansal hizmetleri, banka, aracı kurum ve sigorta şirketlerini alternatif dağıtım kanallarından daha yaygın faydalanmaya doğru iteklemiştir. Başlarda maliyet avantajı olarak kullanılan bu teknolojiler, zamanla pazarlama amaçlı müşteri kazanımına yönelmiş, sosyal medyanın gelişiminin de etkisi ile zaman içerisinde fintech, insurtech, regtech gibi kavramlar ile finansal aracıların ve servis sağlayıcıların klasik tanımların dışına çıkmasına yol açmıştır (Alt vd., 2018, pp.235-243). Bu süreçte elektronik para diğer dijital varlıklar (blok zincirleri) ile farklılaşarak zaman içerisinde kripto paralarla merkez bankacılığının dışına çıkmıştır. Bu şekilde bankacııık, sigortacılık, borsacılık gibi finansal hizmetler ve bunlara dair ürünler yatırımcıların portföylerinde çeşitlenirken, Foreks piyasalarda emtia, döviz, hisse senedi, tahvil gibi ürünlerin arasına bunların türevleri ve kripto para gibi diğer yatıım enstrümanları da eklenmiştir. 2015 sonrasında daha çok ve gündeme hızla giren Endüstri 4.0. teknolojileri ile başta yatırım bankacılığı olmak üzere bankacılığın ve diğer finansal hizmetlerin gelişmesi ve değişmesi daha da kaçınılmaz olacaktır. Para ve sermaye piyasalarında hala kripto paraların ne olduğuna dair tartışmalar sürerken, Türkiye gibi kendi dijital paralarını çıkarmayı planlayan merkez bankalarının (Günen, Fintechtime.com, 2019, ET:2020) yanında mega projelerin finansmanında ya da başka bir dayanak varlığa (örneğin petrol) dayalı dijital (kripto) para arzı düşünen kamu kurumları (Chohan, 2018, pp.1-9) ve Facebook gibi küresel şirketlerin de kendi paralarını çıkararak girmek istediği (dalgalanması az olan) kripto para cinsi stablecoin (Mita, 2019, pp.1-7) uygulamaları da gündeme gelmeye başlamıştır.

Öte yandan Antarktika başta olmak üzere iklim değişikliği ile eriyen buzullar (ile küresel ticaretin Süveyş Kanalı yerine Arktik Denizi'ne doğru kayması olasılı̆̆ı), Avustralya ve Kaliforniya'da uzun süre söndürülemeyen yangınlar, mega depremler ve tsunamiler ya da İzlanda'daki yanardağ patlaması ekstrem risk doğuran doğa olaylarına bir örnektir. Başta havacılık, turizm sektörü dahil birçok küresel ticareti ve hizmeti etkileyen, genelde iklim değişikliği kaynaklı bu doğa olaylarının ekstrem risklerinin olumsuz ekonomik etkileri görülmekte ve başta borsalar olmak üzere yatırımcıyı hızla tedirgin etmektedir (Başoğlu, 2014, ss.175-196).

Sars, Mers, Ebola, Zika, Aids, Influenza gibi bulaşıcı salgın hastalıkların ise bölgesel ekonomiler üzerindeki etkileri ilk defa Coronavirus (COVID-19) pandemi riski ile küresel ekonomi ve piyasalar üzerine sıçramıştır. Bu şekilde Uzakdoğu Borsalarında başlayan satış dalgası ABD piyasalarına sıçramış ve 2020 yılının ilk çeyreğinde hisse değerlerinin erimesine yol açmış ve bu süreçte yatırımcıların güvenli liman arayışlarında tercih ABD doları, altın ve başta ABD tahvilleri olmuştur (NYTimes.com, 2020, ET:2020). Kripto para piyasasında da Bitcoin ile önemli bir geri çekilme borsalara benzer şekilde yaşanmıştır (Jana \& Das, 2020, pp.1-28). Coronavirus salgının Çin ekonomisinden hareketle dünya büyümesine olumsuz etkisi Sars virüsünden daha çok olması beklenmekte olup, tedarik zincirine olumsuz etki yaratması kaçınılmazdır (Ayittey vd., 2020, pp.1-3).

Öte yandan, tüm bu gelişmelerin yanında başta Ortadoğu olmak üzere Akdeniz Havzasında yaşanan siyasi gelişmeler ve gerginlikler ile Fransa, Hong Kong, Şili gibi birçok ülkede yaşanan halk hareketleri piyasaları tedirgin etmektedir. Brexit ile İngilltere (Londra) gibi bir finans merkezinin Avrupa Birliği gibi dünyanın en önemli ekonomik oluşumunu terk ediyor olmasının da yatırım bankacılığı, borsalar, Foreks piyasalar üzerinde kaçınılmaz etki ve sonuçları bulunmaktadır. Nitekim 2021 yılından itibaren LIBOR yerine SONIA faiz ortalamasının geçecek olmasının da dövizli işlemler üzerinden faizlerde veya Foreks işlemlerde dalgalanma etkisini tetiklemesi muhtemelden öte artık gerçektir (Wilner, 2018, pp.64-79).

Bu gelişmelere ek olarak 2016 ABD Başkanlık seçimleri ile iktidara gelen Donald Trump Hükümetinin (seçim beyannamesinde yer alan) küreselleşme karşıtı uygulamaları ile kur savaşlarına ticaret savaşlarını da eklemiştir. Trans-Pasifik Anlaşması ve Paris İklim Anlaşmasından çekilmesinin yanında NAFTA Anlaşmasını yenilemiş, başta Çin olmak üzere birçok ülkeye vergi ve tarife uygulamaları başlatmıştır (Noland, 2018, pp.262-278). Çin ile ilk faz ticaret anlaşması Ocak 2020 tarihinde imzalanmış ancak Coronavirus nedeni ile uygulaması ertelenmiştir. Ticaret savaşları olarak adlandıılan bu gelişmelerin yine küresel finansal piyasalar üzerinde önemli etkileri olmaktadır. Avrupa Merkez Bankası'nın bankalara uyguladığı eksi faizler kredi aktarım mekanizmasına fayda etmediği gibi dünyada yaklaşık 17 trilyon dolarlık tahvil yatırımı negatif reel faiz almayı kabul etmektedir (Bottero vd., 2019, pp.1-59).

Tüm bu gelişmeler net bir şekilde göstermektedir ki kapitalist sistem ve modern yatırım anlayışları yerini alternatif ve teknolojik gelişmelerle kompanse etmeye çalışmaktadır. Klasik ve modern portföy yaklaşımlarının dışında davranışsal finans ile yatırımcıların yatırım kararlarının farklı unsurlar ile şekillendiği artık akademide kabul görmektedir. Bu doğrultuda yatırımcıları sosyal medyadaki gürültü riski dâhil tüm bu başlıklardan etkilenerek yatırım kararlarını şekillendirdiğini iddia etmek zor olmayacaktır. Ancak bu süreçte güvenli yatıım limanlarının da artık eskisi gibi tercih edilmediği ve birlikte ya da ayrı yönlerde hareket eden yatırım ürünlerinin beklenenden farklı yönde ilerleyebildiği görülmektedir. Son Coronavirus salgını ile yatırımcıların altın, dolar tercihi birlikte hareket ederken, Japon yeni, İsviçre frangı ve Bitcoin gibi yatırımcılar tarafından tercih edilen güvenli olarak sayılabilecek paraların değerlerinde düşüş görüldüğü bir piyasa verisidir. 
Bu bilgiler ışığında bu çalışmada ticaret savaşları sonrası yukarıda bahsi geçen diğer tali etkenler ile yatırımcı tercihlerinde güvenli liman arayışında ve tercihinde bir farklılık olup olmadığı araştırılmışır. Ticaret savaşı, rejim değişimi ve yatırım bankacılığı konusu olan kripto para, Foreks piyasa, altın emtia yatırımı gibi ilgili konu başlıklarına dair literatür taraması yapılmıştır. Sonrasında küresel parasal sistemde son yılların en yıkıcı dönüşümü olarak adlandırılan kripto para piyasasının pazar payı lideri Bitcoin ile altın, gümüş gibi insanlık ve para tarihinde önemli olan iki emtia ve dünyada baz para olan dolar ve Euro dışında kalan Japon yeni ve İsviçre frangı arasındaki yatırımcı davranışları ve tercihleri Markow Rejim Değişim Modeli ile incelenmiştir. İleride analizlerde görüleceği üzere, ticaret savaşlarının resmi olarak başladığı yer sayılabilecek olan çelik ve demir vergisinin ilk uygulandığı tarih ile FED'in New York FED üzerinden tekrar bilanço genişletme kararı aldığı tarih aralığı dikkate alınmıştır. Bu dönemde ticaret savaşlarının küresel piyasalara ve güvenli yatırım tercihlerine etkisinin olduğu dönemde Bitcoin tercihine yönelik yatırımcı davranışında bir değişiklik olup olmadı̆̆ı incelenmiştir.

Sonuç olarak, ilk rejim olan yükselen piyasalarda (boğa) gümüş, Japon yeni ve İsviçre frangının Bitcoin yatırım tercihlerini etkilediği, diğer rejimde yani ayı piyasasında ise herhangi bir etkileşim olmadığı görülmüştür. Bitcoin'de ise genelde bu dönemde ayı piyasasının hâkim olduğu görülmüştür. Buradan çıkarılacak sonuç, ticaret savaşlarının olumsuz etkisi ile Bitcoin yatırım tercihleri arasında birinci seviyeden bir ilişki görülemeyeceğidir. Ancak küreselleşmenin olumlu etkilerini Endüstri 4.0. gelişmeleri ile değerlendirmek söz konusu olursa kripto para piyasasının başta Bitcoin olmak üzere yatırım bankacılı̆̆ında ve yatırımcı tercihlerinde 2017 öncesi gibi önemli bir yer tutabileceği beklentisidir. Sonraki çalışmalarda, merkez bankalarının ve kamunun dijital para arzlarının ve kripto para piyasalarının, Washington ve Pekin Konsensüsleri ile Bretton Woods kurumları, dış ticaret, sermaye hareketleri, ödeme sistemleri üzerindeki etkileşimlerinin incelenmesi bu alandaki yazına önemli bir boyut açacak ve bankacılık, sermaye piyasası adına önemli katkı sağlayabilecektir.

Bu çalışmada ticaret savaşları, yatırım ürünleri, çalışmada kullanılan model ile ilgili literatür taraması sonrasında Bitcoin ve güvenli sayılabilecek yatırım ürünleri arasındaki piyasa rejim değişikliği incelenmiştir. Markow Rejim Değişimi Modeli ilgili veri setine uygulanmış ve yatırımcı davranışı analize konu ürünler arasında değerlendirilmiştir. Sonuç olarak farklı rejimler ve yatırım ürünleri adına yatırım bankacılığında, finansal piyasalarda dikkate alınabilecek çıkarımlar özetlenmiştir.

\section{LITERATÜR INCELEMESI}

Literatür taramasında analiz yöntemine dair örneklerin yanında yatırım enstrümanlarının çalışma konusu ile ilgili olanlarına odaklanılmıştır. Foreks piyasalarda önde gelen döviz cinslerinin yanında başta Bitcoin olmak üzere kripto paralar ile altın ve çeşitli borsa endekslerine yönelik araştırmalar özetlenmiştir. Ayrıca ticaret savaşlarının farklı ekonomik rejimlerde güvenli liman olabilecek yatırım boyutlarında etkisi olup olmadığına dair yapılan araştırmalar da kısaca eklenmiştir.

\subsection{Markow Rejim Değişimi Literatür Örnekleri}

Engel (1994) Markow Rejim Değişimi Modelinin Foreks piyasalarda döviz cinsleri üzerindeki ilk önemli uygulama örneklerinden biridir. Her ne kadar genel olarak döviz kurlarının öngörülmesinde rassal yürüyüş ile modelin işlemediğini sonuç olarak vurgulasa da 1986-1991 yıllarını kapsayan analizinde İsviçre frangı için modelin daha güçlü olduğunu, dolar/TL ve dolar/yen forward kurunda ortalama sapmanın çok az olduğunu belirtmiştir.

Evci, Şak ve Karaağaç (2016) tarihli çalışmasında Markow Rejim Değişim Modelleri ile BisT ve Londra altın fiyatlarındaki değişimi incelemişlerdir. Buna göre, altın yatırımcısının hangi rejimde olduğunu bilmesi durumunda burada uzun süreli kaldığı sonucuna ulaşmışlardır. Yani düşük veya yüksek getirili rejimlerde olduğunu görmeleri halinde burada yatırım kararlarını doğru yönde verdikleri ve altının güvenli liman olduğu sonucuna varmışlardır.

Kodama, Pichl ve Kaizoji (2017) çalışmalarında “Hidden Markow Model” ve 1990 tarihli Elman'ın "Recurrent Neural Network (RNN)" modelleri ile Euro bazlı Coinbase Borsasındaki (BTC/EUR) Euro bazlı Bitcoin fiyatlarını analiz etmişler ve ortalama sapmanın dalgalanma ile korelasyon gösterdiğini ve yüksek dalgalanmaların yaşandığı kripto para piyasasında sinir ağları modelinin işlediğini görmüşlerdir.

Koy (2017) tarihli çalışmasında BiST spot ve vadeli piyasaları arasında yatırımcıların piyasadaki gelişmeleri dikkate alarak yatırım tercihlerini değiştirdiğini ve dalgalanmaların daralma (ayı) veya genişleme (boğa) piyasalarına neden olduğunu ifade ederek yatırım bankacılığı üzerinden borsada yatırımcıların neden olduğu rejim değişimini incelemiştir. Markow Rejim Değişim Modeli kısaca rastlantı dâhilinde değişkenlerin farklı rejimler arasındaki geçişleri analiz etmektedir. Hamilton $(1988,1989)$ tarafından tek değişkenli doğrusal olmayan yöntemle $A B D$ ekonomisi verileri iş döngüsü ile rejim geçişleri analiz edilmiştir. "Markov Değişim Vektör Otoregresif Modeli (MS-VAR)" ile analizlerinin sonucunda spot piyasanın vadeli piyasayı daha ağırlıklı etkilediği ve karşııılı etkileşim olduğu sonucuna varılmıştır.

Kula ve Baykut (2017) tarihli çalışmasında Markow Rejim Değişimi GARCH Modeli ile BisT Bankacılık Endeksi'ndeki oynaklığı (volatilite) doğrusal ARCH ve GARCH modelleri dışında doğrusal olmayan bir modelle analiz etmek istemişlerdir. Sonuç olarak, 
Bankacılık Endeksi'nin düşük riskli rejim tercihindeki yatırımcılar açısından talep gördüğünü, ellerinde uzun süreli tutma şeklinde davranışsal finans ışığında da değerlendirilebileceği sonucuna varmışlardır.

Rechard (2019) tarihli tez çalışmasında, iki ayrı bölüm olarak Bitcoin ve merkez bankalarının para politikaları üzerine FED parasal genişleme ve sıkılaştırma dönemlerini dikkate alarak ANOVA, Markow Rejim Değişimi Modelini de kullandığı kapsamlı bir analiz yapmıştır.

Bouoiyour, Selmi ve Wohar (2019) çalışmasında Bitcoin ile altının düşük ve yüksek rejim dönemlerini Markow Rejim Değişim Modeli ile incelemişler ve sonuç olarak birbirlerinin ikamesi değil güvenli yatırım ürünü olarak tamamlayıcı oldukları ve spesifik siyasi ve ekonomik olaylardan aynı şekilde etkilendikleri sonucuna varmışlardır.

Koutmos (2019) çalışmasında, Markow Rejim Değişim Modeli ile analizinde düşük ve yüksek getirili rejimler arasında Bitcoin fiyatlarının literatürün geneline benzer şekilde hisse senedi fiyatlarından ve ekonomik değişkenlerden etkilenmediğini ancak diğer finansal varlıklar gibi aynı piyasa riskine açıklık içerdiğini özet olarak vurgulamıştır.

\subsection{Ticaret Savaşları ilgili Literatür Örnekleri}

Steinbock (2018) tarihli çalışmasında ABD-Çin ticaret savaşının yükselmesinin küresel resesyona ve bölgesel çatışmalara dönüşebileceğini öngörmüş, internet, inovasyon üzerinden teknolojik rekabete değinmiştir.

Liu ve Woo (2018) çalışmasında Çin ekonomisindeki yükseliş, Çin kur rejimi ile oluşan dış ticaret ve cari fazla gelişmeleri, teknolojideki yükseliş ile ABD’nin Çin'in gelişimini engellemek için ekonomik rekabeti stratejik rekabetin önüne koyduğunu öne sürmüşlerdir.

Gözgör, Tiwari, Demir ve Akron (2019) çalışmalarında Bitcoin ile ABD Ticaret Politikası Belirsizlik Endeksi arasındaki ilişkiye bakmışlardır. Sonuç olarak ticaretteki belirsizliklerin Bitcoin getirilerini olumsuz etkilediği sonucuna varmışlardır.

Evans (2019) çalışmasında Trumponomics adını verdiği "Make America Great Again" seçim mottosu ile ABD-Çin ticaret savaşının başladığını, sonuç olarak ise tüketiciler adına ürün fiyatlarının yükseleceği, ithalat maliyetlerinin artacağı, yatırımcıların tedirgin olacağı, bazı yatırımcıların güvenli liman olarak Bitcoin ve bazı kripto paralara yöneleceği, ticaret savaşının kur savaşlarına dönebileceği, gelişmiş ekonomiler dahil dünya ticaretinin bundan olumsuz etkileneceğini ifade etmiştir.

Plakandaras, Bouri ve Gupta (2019) çalışmalarında farklı regresyon analizleri ile vardıkları sonuçta Bitcoin fiyat hareketleri ile ticaret belirsizlikleri arasında bir ilişki görememişlerdir.

Khan (2019) çalışmasında ABD, Çin ve Avrupa Birliği arasında ticaret savaşlarının büyüme üzerindeki etkilerini incelemiştir. Savaşın limitli kalması halinde $A B D$ ve Çin ekonomisi üzerinden dünya ekonomisine etkisinin $-0,5 \%$, diğer ülkelerin, örneğin NAFTA, buna katılması halinde $-3 \%$ oranına kadar çıkabileceğini sonuç olarak ifade etmiştir

Burggraf (2020), ABD seçimleri ile Bitcoin arasındaki siyasi belirsizlik etkilerini kantil regresyon ile incelemiş ve seçimlerden 36 ay öncesinde etkinin en yüksek olduğunu, Bitcoin'in getirisinde siyasi belirsizlik durumunda düşüş olduğu sonucuna varmıştır.

Canöz (2020) kitap bölümü çalışmasında, Bitcoin işlem hacmi ile ABD'nin parasal büyümesi arasındaki ilişkiyi Temmuz 2010Temmuz 2019 arası dönemini ele alarak simetrik nedensellik ve zamanla değişen simetrik nedensellik testleriyle analiz etmiştir. Simetrik nedensellik testi sonuçları, iki değişken arasında bir ilişki olmadığını göstermiştir. Zamanla değişen simetrik nedensellik testi de çoğunlukla aynı bulguyu desteklese de ABD ve Çin ticaret savaşlarının etkisiyle küresel ekonominin daralma şiddetinin arttığı Nisan 2019 ve Temmuz 2019 döneminde nedensel bir bulguyu tespit etmiştir. Bu bulgunun nedenini ise Bitcoin'in güvenli liman olarak görülmesi olasılığı olarak açıklamıştır.

\subsection{Kripto Para, Foreks ve Emtia Piyasaları Literatür Örnekleri}

Berke, Özcan ve Dizdarlar (2014) tarihli çalışmalarında, Fama'nın 1969 ve 1970'te ifade ettiği piyasa etkinliği, spot ve vadeli (forward) döviz kurları üzerinden Foreks piyasasının Türkiye özelinde analiz etmişlerdir. MAKi Eşbütünleşme Testi ve FMOLS Tahmin Sonuçları ile zayıf formda döviz piyasası etkin iken yarı güçlü formda etkin olmadığını, forward kurların spot kurun tahmininde etkili olmadığı özet sonucuna varmışlardır.

Dirican ve Canöz (2017) tarihli çalışmalarında, Türkiye'de akademik yazında ilk olacak şekilde, Bitcoin ile önde gelen borsa endeksleri arasında ARDL Sınır Testi yapmış ve sonuç olarak Dow30, S\&P500, Nasdaq100 ve Chinaa50 endeksleri ile Bitcoin fiyatları arasında analiz döneminde eşbütünleşme görmüşlerdir. BIST100, FTSE100 and NIKKEI225 endeksleri ile bir nedensellik görmemişlerdir. 
Erdoğdu (2017) çalışmasında altının ons fiyatı ile petrol, gümüş, ABD doları, Dow30 (DJIA), FED faiz oranları ve ABD Tüfe oranları arasındaki ilişkiye GARCH modeli ile bakmış ve ekonomik büyüme dönemlerinde dalgalanmaların azaldığını, altın ons fiyatı ile dolar, petrol, gümüş fiyatları arasında lineer negatif korelasyon görmüştür.

Harihara Sudhan ve Subramanian (2018) tarihli çalışmalarında Bitcoin'in bir risk yönetim (hedging) enstrümanı olup olamayacağını analiz etmişler ve Bitcoin'in hisse senedi piyasasındaki dalgalanmalara karşı bağışık olduğunu, Bitcoin'in diğer yatırım ürünlerine göre uzun süreli dalgalanma sürekliliğinin daha az olduğunu bulgu olarak görmüşlerdir. SP\&500 ve ABD doları ve Euro ile ABD doları ve Japon yenine karşı yaptıkları analizde ise Bitcoin'in ABD doları ve Japon yenine karşı daha iyi bir dengeleme (hedging) ürünü olduğunu bulmuşlardır.

Baumohl (2018) çalışmasında Foreks piyasasındaki döviz cinsleri ile kripto para piyasasının önde gelen coin'leri arasındaki ilişkileri "Detrended moving-average cross-correlation analysis (DMCA)" ile bakmış ve çarpıcı bir şekilde bankalararası para transferinde kullanılan Ripple'ın (XRP) güvenli bir yatırım ürünü olduğunu, diğer kripto paralar ile döviz cinslerinin kantiller bazında farklı seviyelerde çapraz bağlantılarının olduğunu görmüş ve portföy çeşitlendirmesi ile ancak risk ve getiri dengesinin sağlanabileceğini kısaca belirtmiştir.

Cheong (2019) çalışmasında dört kripto para cinsi ile Foreks piyasalarda altın, dolar, yen, pound ve Euro arasında, Fama \& Macbeth'in 1973'teki regresyon modeli ile analiz gerçekleştirmiş ve sonuç olarak bunların kombinasyonlarından oluşan yatırım portföylerinde kripto paraların döviz riski yönetiminde denge ve risk azaltımı (hedging) adına daha basit yatırım ürünleri olduğu sonucuna varmıştır. Dijital varlık olarak kripto paraların küresel ekonomiden ve siyasi belirsizlikten daha az etkilenmesinin yanında $A B D$ ekonomisine duyarlı olduğunu, altının hala bir güvenli liman olarak görüldüğü çıkarımlarını ifade ederken, yazındaki bulguların tersine analizine konu olan döviz cinslerinden (Foreks) oluşan portföy çeşitlendirmesinin riskleri azaltmadığını belirtmiştir.

Bergsli ve Lind (2019) tarihli yüksek lisans tezinde SP500, altın, gümüş, yen ve İsviçre frangı dâhil altı döviz birimi ile Heterojen Otoregresif (HAR) yaptıkları analizde Bitcoin fiyatlarının ve dalgalanmalarının bunlardan doğrusal olarak etkilenmediği sonucuna varmışlardır. Aynı çalışmada İsviçre ve Japon Merkez Bankaları dâhil altı gelişmiş ekonomi merkez bankalarının faiz kararlarının da benzer şekilde etkisiz olduğu sonucuna varmışlardır.

Virk (2019) çalışmasında Bitcoin ile Foreks piyasalar arasındaki ilişkiye bakmış ve fiat paralar ile makroekonomik göstergelerin Bitcoin fiyatlaması ile bir korelasyonu olmadığını görmüştür. Bitcoin yatırımının bir hedging işleminden çok portföy getirisinin maksimizasyonu için kullanıldığını, dalgalanmasının (volatilite) yüksek olduğunu GARCH modeli ile ortaya koymuştur.

Baur ve Hoang (2019) çalışmasında, stablecoin yani belli bir sepete veya enstrümana bağlı kripto paralar ile Bitcoin dalgalanmaları arasındaki ilişkiye bakmışlardır. Tether başta olmak üzere bu dengeli kripto paraların Bitcoin dalgalanmalarında güvenli liman (yatırım enstrümanı) olarak tercih edildiklerini sonuç olarak bulmuşlardır.

De Cnijf (2019) yüksek lisans tezinde altın, STOXX600 Europe, VIX ve SP\&500 arasındaki ilişkileri kantil regresyon ile analiz etmiş ve sonuç olarak altının dalgalanma dönemlerinde ons olarak güvenli liman ancak endeks olması halinde ters yönlü etkilendiği sonucuna varmıştır.

\section{VERI VE METODOLOJi}

\subsection{Veri}

Çalışmanın veri seti Ek.1'de yer aldığı üzere, 04/03/2018 ve 01/09/2019 arası dönemi kapsayan 79 haftalık zaman serisinden oluşmaktadır. Eviews 9.5 programı vasıtası ile analiz edilmiştir. Bu dönemin incelenme sebebi, ABD tarafından Çin ile (başta) başlatılan ticaret savaşının resmi olarak başlangıç tarihinin 01/03/2018 olarak kabul edilmesidir. Bu şekilde, ticaret savaşlarının, ABD Başkanı Jr.Donald Trump başkanlık kararı ile 01 Mart 2018'de tüm ilgili ticaret ortaklarına ithal edilen çelik ürünleri ve alüminyumda tarife olarak $10 \%$ ila $25 \%$ ek yük bindirecek şekilde gümrük vergisi uygulayacağını duyurması ile resmi olarak başlamış olduğu kabul edilmektedir (Palacıoğlu, www.istka.org.tr, 2018, ss.1-12).

Tablo 1'de çalışmanın amacı doğrultusunda analiz edilen değişkenler sunulmaktadır.

Tablo 1: Çalışmada Kullanılan Değişkenler

\begin{tabular}{|l|c|c|c|c|}
\hline Değişkenler & Kurlar & Açıklama & Araç Çeşitleri & Kısaltma \\
\hline Bitcoin & BTC/USD & Bitcoin Amerikan Doları & Forex-Bitfinex & BTC \\
\hline Japon Yeni & JPY/USD & Japon Yeni Amerikan Doları & Forex & JPY \\
\hline İsviçre Frangı & CHF/USD & İsviçre Frangı Amerikan Doları & Forex & CHF \\
\hline Altın & XAU/USD & Altın Spot Amerikan Doları & Forex & XAU \\
\hline Gümüş & XAG/USD & Gümüş Spot Amerikan Doları & Forex & XAG \\
\hline
\end{tabular}

Kaynak: Yazar tarafından oluşturulmuştur. 
Çalışmada değişkenlerin ham değerleri kullanılmış ve aşağıda bunların çalışma dönemi içerisindeki değişimleri grafik görünümü özet bütünsel şekil olarak sunulmuştur.

\section{Şekil 1: Değişkenlere Ait Zaman Serilerinin Grafik Görünümü}

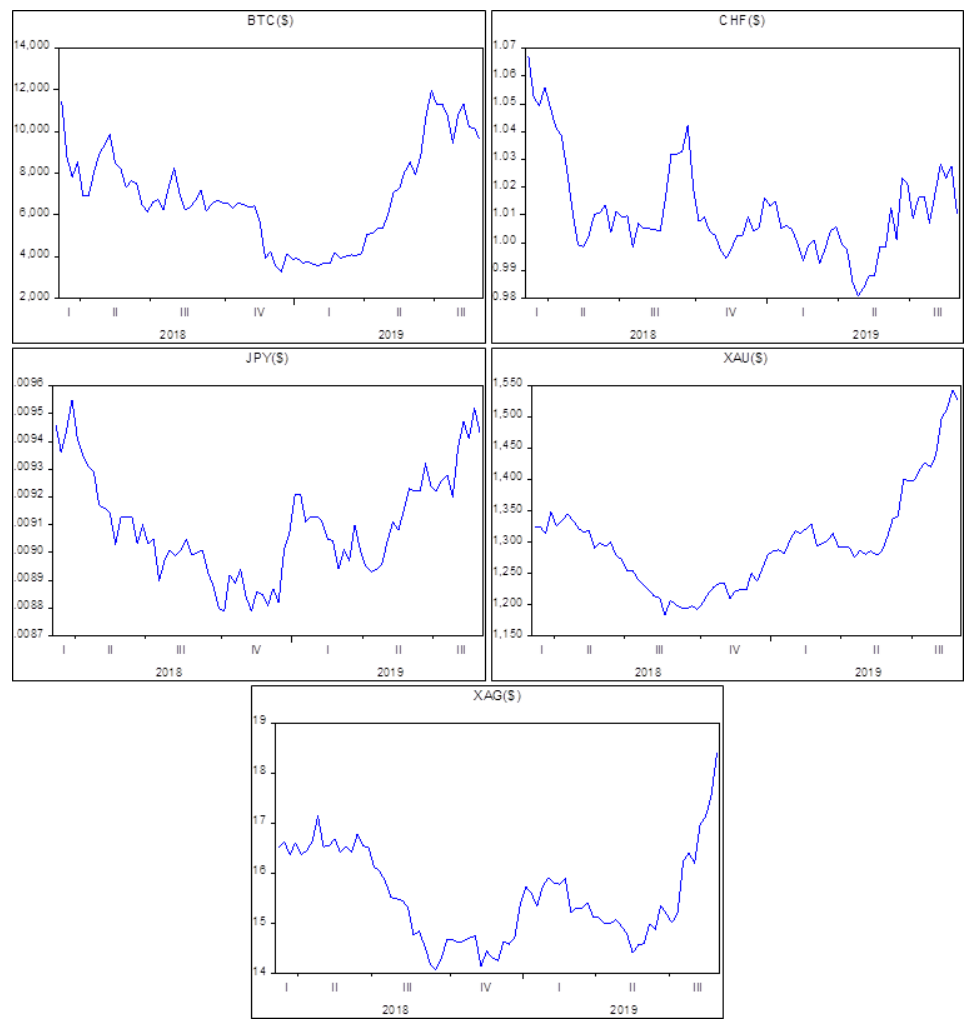

Kaynak: Veri setinin programda işlenmesi ile yazar tarafından oluşturulmuştur.

\subsection{Metodoloji}

Hamilton $(1988,1989)$ tarafından ekonometri literatürüne kazandırılan Markov Rejim Değişim Modeli, rejimdeki değişiklikleri belirlemek adına birçok ekonomik ve finansal uygulamada kullanılmıştır (Garcia, 1998, s. 763). Model, t ve t-1 şeklindeki gösterilen farklı periyotlardaki rejimlerin karşılıklı ilişkilerinin tespitine ve analizine yöneliktir. Matematiksel olarak aşağıdaki şekilde ifade edilmektedir:

$$
\text { " } y_{t}=a_{s t}+x_{t} B s_{t}+\epsilon_{t} \quad \epsilon_{t} \sim \text { i.i.d. } N\left(0, \sigma_{\epsilon, s t 2}\right) "
$$

Formüldeki $y_{t}$ Bitcoin fiyatına, $x_{t}$ bağımsız olarak kabul edilen değişkenlerin temsiline, $s_{t}$ rejime dair değişkene karşılık gelmektedir.

Modelde rejimler arasındaki değişimlerin olasılık fonksiyonunun yer alması (olasılık fonksiyonu) şeklinde ifade edilecektir. Modelin kapsadığı rejimler (dönemleri) rastlantısal değişken olarak $s t$ aracılığı ile belirtilmektedir. Bu halde $s t$ rejimine dair değişken olasılık değeri kendisinden evvel gelen rejimin devresine bağlantılı olacak şekilde aşağıdaki gibi gösterilebilir (Avcı vd., 2016, s. 463-475):

$$
\text { " } P\left\{s_{t}=j \mid s_{t-1}=i\right\}=P\left\{s_{t}=j \mid s_{t-1}=i . s_{t-2}=k \ldots . .\right\}=p_{i j ”}
$$

Eşitlik ilk sırada Markov Rejm Modeli zincirindeki rejimler arası geçişlerin olasıılı̆ını (i'den j'ye geçiş olasılıkları) ifade etmektedir. (Avcı vd., 2016, s. 466). 


\section{BULGULAR VE TARTISSMALAR}

Zaman serileri ile yapılan ekonometrik analizlerde bu serilerin birim kök taşıyıp taşımadığının incelenmesi çoğunlukla gereklidir. Buradan hareketle, çalışmada kullanılan değişkenlere, en çok tercih edilen birim kök testleri arasında bulunan "Augmented Dickey-Fuller (ADF)" uygulanmıştır. Bu teste ait sonuçlar Tablo 2.'de yer almaktadır.

Tablo 2: ADF Birim Kök Testi Sonuçları

\begin{tabular}{|c|c|c|c|c|}
\hline “Değişkenler & & & Trendli i & abitli \\
\hline \multirow{6}{*}{$B T C$} & \multicolumn{2}{|c|}{ Düzey Değer } & \multicolumn{2}{|c|}{ Düzey Değer } \\
\hline & t-istatistik & olasılık & t-istatistik & olasılık \\
\hline & $-1,915000$ & 0,3239 & $-2,051322$ & 0,5642 \\
\hline & \multicolumn{2}{|c|}{ Birinci Fark Değeri } & \multicolumn{2}{|c|}{ Birinci Fark Değeri } \\
\hline & t-istatistik & olasılık & t-istatistik & olasilık \\
\hline & $-8,448558$ & 0,0000 & $-8,492034$ & 0,0000 \\
\hline \multirow{6}{*}{$X A G$} & \multicolumn{2}{|c|}{ Düzey Değer } & \multicolumn{2}{|c|}{ Düzey Değer } \\
\hline & $t$-istatistik & olasılık & t-istatistik & olasilık \\
\hline & $-0,602820$ & 0,9491 & 0,646561 & 0,9995 \\
\hline & \multicolumn{2}{|c|}{ Birinci Fark Değeri } & \multicolumn{2}{|c|}{ Birinci Fark Değeri } \\
\hline & t-istatistik & olasılık & t-istatistik & olasilık \\
\hline & $-8,129559$ & 0,0000 & $-8,823518$ & 0,0000 \\
\hline \multirow{6}{*}{$\mathrm{CHF}$} & \multicolumn{2}{|c|}{ Düzey Değer } & \multicolumn{2}{|c|}{ Düzey Değer } \\
\hline & t-istatistik & olasılık & t-istatistik & olasilık \\
\hline & $-3,645780$ & 0,0069 & $-3,331840$ & 0,0687 \\
\hline & & & \multicolumn{2}{|c|}{ Birinci Fark Değeri } \\
\hline & & & t-istatistik & olasilık \\
\hline & & & $-9,026059$ & 0,0000 \\
\hline \multirow{6}{*}{$J P Y$} & \multicolumn{2}{|c|}{ Düzey Değer } & \multicolumn{2}{|c|}{ Düzey Değer } \\
\hline & t-istatistik & olasılık & t-istatistik & olasilık \\
\hline & $-1,903881$ & 0,3290 & $-2,025160$ & 0,5784 \\
\hline & Birinci $F c$ & Değeri & Birinci Fa & Değeri \\
\hline & t-istatistik & olasılık & t-istatistik & olasilık \\
\hline & $-10,28503$ & 0,0001 & $-10,69627$ & 0,0000 \\
\hline \multirow{6}{*}{$X A U$} & \multicolumn{2}{|c|}{ Düzey Değer } & \multicolumn{2}{|c|}{ Düzey Değer } \\
\hline & t-istatistik & olasılık & t-istatistik & olasilık \\
\hline & 1,351403 & 0,9987 & 0,646561 & 0,9995 \\
\hline & \multicolumn{2}{|c|}{ Birinci Fark Değeri } & \multicolumn{2}{|c|}{ Birinci Fark Değeri } \\
\hline & t-istatistik & olasılık & t-istatistik & olasilık \\
\hline & $-8,679654$ & 0,0000 & $-8,679654$ & $0,0000^{\prime \prime}$ \\
\hline
\end{tabular}

Kaynak: Veri setinin programda işlenmesi ile yazar tarafından oluşturulmuştur.

Tablo 2. incelendiğinde, BTC, XAG, XAU ve JPY değişkenlerinin sabitli ve trendli yine sabitli modeldeyse düzey değerinde durağan olmadığı görülmektedir (olasılık>0,05). Bu değişkenlerin birinci farkları alınarak durağan hale getirilmişlerdir. CHF değişkeni ise sabitli modelde düzeyde durağan iken (olasılık<0,05), trendli ve sabitli modelde birinci farkta durağandır (olasılık $>0,05$ ). Bu karmaşıklığı önlemek adına CHF değişkenine ait Şekil 1.'deki grafik incelenmiş ve trendli bir yapıya sahip olmasından dolayı birinci farkı alınarak durağanlaştırılmıştır.

Serilerin durağanlaştırıması sonrası, bunlara çalışma amacına uygun olarak Markov Rejim Değişim Modeli uygulanmıştır. Açıklayıcı gücü yüksek en uygun model tahmin edilmeye çalışılmıştır. Rejim sayısına bilgi kriterlerine bakılarak karar verilmiştir. Böylece iki rejimli bir modelde karar kılınmıştır. Modele dair sonuçların yer aldığı tablo şu şekildedir:

Tablo 3: Markov Rejim Değişim Modeli Sonuçları

\begin{tabular}{|c|c|c|c|c|}
\hline "Bağımlı Değişken: & DBTC \\
\hline Değişkenler & Katsayı & Standart Hata & z-istatistik & olasılık \\
\hline \multicolumn{5}{|c|}{ Rejim 1 } \\
\hline Sabit Terim & 85,79406 & 218,7756 & 3,921555 & $0,0001^{* *}$ \\
\hline DCHF & 1039,989 & 22758,40 & 4,569694 & $0,0000^{* *}$ \\
\hline
\end{tabular}




\begin{tabular}{|c|c|c|c|c|}
\hline DJPY & -3056674, & 3552704, & $-8,603794$ & $0,0000^{* *}$ \\
\hline DXAG & $-604,9030$ & 110,6117 & $-5,468706$ & $0,0000^{* *}$ \\
\hline DXAU & 28,47824 & 26,85136 & 1,060588 & 0,2889 \\
\hline LOG(SIGMA) & 4,078880 & 0,248457 & 16,41682 & $0,0000^{* *}$ \\
\hline \multicolumn{5}{|c|}{ Rejim 2 } \\
\hline Sabit Terim & $-61,03846$ & 10,98893 & $-0,555454$ & 0,5786 \\
\hline DCHF & 3206,157 & 1771,822 & 0,180953 & 0,8564 \\
\hline DJPY & 286033,6 & 181390,3 & 1,576896 & 0,1148 \\
\hline DXAG & $-661,2108$ & 469,2640 & $-1,409038$ & 0,1588 \\
\hline DXAU & 1,146883 & 1,011083 & 1,134312 & 0,2567 \\
\hline LOG(SIGMA) & 6,637849 & 0,100296 & 66,18247 & $0,0000^{* *}$ \\
\hline \multicolumn{5}{|c|}{ Geçiş Matrisi Parametreleri } \\
\hline P11-C & 0,594808 & 0,673432 & 0,883249 & 0,3771 \\
\hline P21-C & $-2,440366$ & 0,674602 & $-3,617489$ & $0,0003^{* *}$ \\
\hline \multicolumn{5}{|c|}{ Modele Ait Tanımlayıcı istatistikler } \\
\hline Mean dependent var & $-23,46282$ & S.D. dependent var & 766,0540 \\
\hline S.E. of regression & 772,5827 & Sum squared resid \\
\hline Durbin-Watson stat & 1,597389 & Log likelihood & 39394342 \\
\hline Akaike info criterion & 15,99985 & Schwarz criterion & $-609,9943$ \\
\hline Hannan-Quinn criter. & 16,16919 " & 1,642285 \\
\hline
\end{tabular}

Not: ** \%5 anlamlılık seviyesini temsil eder.

Kaynak: Veri setinin programda işlenmesi ile yazar tarafından oluşturulmuştur.

Modele göre Rejim 1'in Bitcoin fiyat beklentilerinin iyimser olduğu yani boğa piyasasının hâkim olduğu süreci; Rejim 2'nin ise Bitcoin fiyat beklentilerinin kötümser yani ayı piyasasının hâkim olduğu süreci tanımladığı varsayılmaktadır. Ayı piyasası rejiminde CHF, JPY, XAG ve XAU değişkenlerinin BTC üzerinde istatistiksel olarak anlamlı bir etkisi bulunmadığı anlaşılmaktadır (Her birinin olasılık değeri, 0,05'ten büyüktür). Boğa piyasası rejiminde ise CHF, JPY ve XAG değişkenleri Bitcoin fiyatı üzerinde istatistiksel açıdan anlamlı bir etkiye sahiptir (Her birinin olasılık değeri 0,05'ten küçüktür). Ancak XAU değişkeninin anlamlı bir etkisi bulunmamaktadır.

Rejim 1 ve Rejim 2'nin hangi piyasayı temsil ettiği rejimlere düşen gözlem değerleri yardımı ile anlaşılmaktadır. Bu açıdan rejim özelliklerinin incelenmesi önemlidir. Rejimde kalma ve rejimler arası geçiş olasılıklarının bilinmesi rejimleri ayırmak için fikir vermektedir. Aşağıda rejimde kalma rejim geçiş olasılıkları görülmektedir.

Tablo 4: Rejimde Kalma ve Rejim Geçiş Olasılıkları

\begin{tabular}{|c|c|c|}
\hline “Rejimler & Rejim 1 & Rejim 2 \\
\hline Rejim 1 & 0,644467 & 0,355533 \\
\hline Rejim 2 & 0,080146 & 0,919854 \\
\hline Her Bir Rejim İçin Beklenen Süre (Hafta) \\
\hline Rejim 1 & \multicolumn{2}{|c|}{2,812682} \\
\hline Rejim 2 & 12,47724 ” \\
\hline
\end{tabular}

Kaynak: Veri setinin programda işlenmesi ile yazar tarafından oluşturulmuştur.

Tabloya göre Rejim 1'de iken takip eden haftada Rejim 1 içerisinde kalınma durumunun olasılığı yaklaşık 64\%; Rejim 2'deyse bu rejimde iken takip eden haftada Rejim 2'nin içinde kalmanın olasılığı yaklaşık 92\%'dir. Rejimler arası geçişlerine bakıldığında, Rejim 1'deyken takip eden haftada Rejim 2'ye geçilmesi olasılı̆̆ı yaklaşık 36\%; Rejim 2'deyken Rejim 1'e geçilme olasılığı ise yaklaşık $8 \%$ olduğu anlaşılmaktadır.

Her bir rejim için beklenen süre sırasıyla yaklaşık 2,8 ve 12,47 hafta olarak belirlenmiştir. Bu süreler boğa piyasasını temsil eden Rejim 1'de ortalama 2,8 hafta, ayı piyasasını temsil eden Rejim 2'de ortalama 12 hafta kararlı kalındığını ifade eder. Sonuç olarak, Bitcoin piyasasına hâkim rejimin ayı piyasası rejim olduğu söylenebilir.

\section{SONUÇ}

Literatürdeki benzer çalışmalar ışığında, ticaret savaşlarının resmiyet kazandığı dönem ile ABD Merkez Bankası FED'in tekrar (NY FED üzerinden) parasal genişleme ile bilanço büyütme kararı aldığı dönem arası incelenmiştir. Bitcoin ile güvenli liman olarak kabul edilen İsviçre frangı ve Japon yeni arasında ve insanlık tarihi boyunca parasal sistemlerde önem arz eden ve geçmişte para, günümüzde yatırım ürünü olarak kullanılan altın ve gümüş fiyatları arasında bir rejim değişimi olup olmadığı 
analiz edilmiştir. Bu şekilde Donald Trump başkanlığı sonrası küreselleşmeyi sekteye uğratan ticaret savaşları döneminde, yatırımcıların yatırım tercihlerinde Bitcoin (kripto para piyasasındaki pazar payı nedeni ile diğer kripto paralar için de benzer bir bulgu ileri sürülebilecektir) gibi yeni dijital varlıklara bir yönelim olup olmadığı, diğer güvenli limanlar arasında bir tercih farklıı̆̆ı oluşup oluşmadığı anlaşılmak istenmiştir. Keza, Bitcoin'in altın gibi değerli bir madenin yatırım tercihi anlamında güvenli liman olarak ikame olup olmadığının görülmesi arzulanmıştır. Keza altın fiyatlarıyla genelde aynı yönde hareket eden gümüş yine analizlere katılmış, baz para dolar ve Euro dışında kalan diğer iki güvenli liman olarak görülen Foreks piyasasındaki Japon yeni ve İsviçre frangı özelinde bir geçişkenlik olup olmadığı incelenmek istenmiştir. Pound Brexit ile İngiltere'nin Avrupa Birliği dışında çıkma yönünde almış olduğu referandum kararının analiz döneminde henüz hayata geçip geçmeyeceğine dair belirsizlikler nedeni ile dışarıda bırakılmıştır. Keza Euro da aynı sebeple dolara karşı taraf olarak ve doğal olarak dolar gibi baz para olarak dünya ticaretinde ve finansal piyasalarında tercih edilmesi nedeni ile dışarıda bırakılmıştır. ABD dolarına ve tahvillerine olan eğilimin artması, baz para olması ve Euro ile parite etkisi nedeni ile etkileşimleri yine analiz dışında kalması için bir etkendir.

Bu bilgiler ışığında; Japon yeni ve İsviçre frangı ile Bitcoin fiyatları arasında boğa piyasası döneminde yatırımcıların kararlarının etkilendiği izlenmiştir. Ayı piyasası olarak tabir edilen düşüş rejiminde ise literatür bölümündeki benzer örneklere paralel olarak Bitcoin yatırımları ile güvenli liman (safe haven) olarak tabir edilen altın, gümüş, Japon yeni ve İsviçre frangı arasında bir rejim değişim durumuna rastlanılmamıştır. Aynı dönemde Bitcoin yatırımlarında ise genelde ayı piyasasının görüldüğü dönemlerde rejim 2'de yani ayı piyasası tandanslı yatırım davranışlarında daha uzun kalındığı görülmüştür. Yani Bitcoin özelinde yatırım bankacılığı açııından çıkarılacak bir önemli sonuç, borsaların ve aracı kurumların ayı piyasası yerine boğa piyasası dönemlerinde Bitcoin ve kripto para pazarlama faaliyetlerini daha ön plana çıkarmasının uygun olacağıdır. Keza piyasalardaki dalgalanmalarda literatürdeki araştırmaların farklı yöndeki bulgularına paralel olarak yeni yatırım davranış şekillerinin ortaya çıktığı izlenmektedir.

Buradan çıkarılacak sonuç, ticaret savaşlarının olumsuz etkisi ile Bitcoin yatırım tercihleri arasında birinci seviyeden bir ilişki görülemeyeceğidir. Ancak küreselleşmenin olumlu etkilerini Endüstri 4.0. gelişmeleri ile değerlendirmek söz konusu olursa kripto para piyasasının başta Bitcoin olmak üzere yatırım bankacılığında ve yatırımcı tercihlerinde 2017 öncesi gibi önemli bir yer tutabileceği beklentisidir. Sonraki çalışmalarda, merkez bankalarının dijital para arzlarının ve elektronik para piyasaları ile kripto para piyasalarının, Washington ve Pekin Konsensüsleri ile dış ticaret, sermaye hareketleri üzerindeki etkileri ve etkileşimlerinin incelenmesi bu alandaki yazına önemli bir boyut açacak ve katkı sağlayabilecektir.

\section{REFERENCES}

Alt, R., Beck, R. \& Smits, M.T. (2018). FinTech and the transformation of the financial industry. Electron Markets 28, pp.235-243, 2018. https://doi.org/10.1007/s12525-018-0310-9

Avcı, M. A., Altay, N. O., \& Sulak, H. (2016). Finansal krizlerin öngörüsünde Markov Rejim Değişimi Modeli: gelişmekte olan ülkelere yönelik bir analiz. Süleyman Demirel Üniversitesi iktisadi ve Idari Bilimler Fakültesi Dergisi. 21(2): $463-475$. http://acikerisim.pau.edu.tr/xmlui/handle/11499/28393

Ayittey, FK, Ayittey, MK, Chiwero, NB, Kamasah, JS \& Dzuvor, C. (2020). Economic impacts of Wuhan 2019-nCoV on China and the World. J Med Virol. 2020; pp.1-3. https://doi.org/10.1002/jmv.25706

Başoğlu, A. (2014). Küresel iklim değişikliğinin ekonomik etkileri”, KTÜ Sosyal Bilimler Enstitüsü Dergisi, No: 7, 2014, ss.175-196. http://acikerisim.ktu.edu.tr/jspui/bitstream/123456789/213/1/Tam\%20Metin.pdf, http://www.ktu.edu.tr/dosyalar/sbedergisi 8fd33.pdf.

Baumohl, E. (2018). Are cryptocurrencies connected to Forex? A quantile cross-spectral approach. ZBW - Deutsche Zentralbibliothek fürWirtschaftswissenschaften, Leibniz-Informationszentrum Wirtschaft (Leibniz Information Centrefor Economics), Kiel und Hamburg, 2018, pp.1-18, https://www.econstor.eu/bitstream/10419/174884/1/Baumohl\%20\%282018\%29.pdf.

Baur, Dirk G. \& Hoang, Lai T., A crypto safe haven against Bitcoin. September 21, 2019, pp.1-14. Available at SSRN: https://ssrn.com/abstract=3457688 or http://dx.doi.org/10.2139/ssrn.3457688

Bergsli, L. Ø.\& Lind, A. F. (2019). Impact of the stock market, major currencies, precious metals and central banks on the volatility of Bitcoin. Norwegian University of Science and Technology, Faculty of Economics and Management, Department of Industrial Economics and Technology Management. Master's thesis in Industrial Economics and Technology Management. Supervisor: Peter Molnár. June 2019, pp.172. https://ntnuopen.ntnu.no/ntnu-xmlui/handle/11250/2622859

Berke, B., Özcan, B., \& Dizdarlar, H. I. (2014). Döviz piyasasının etkinliği: Türkiye için bir analiz. Ege Academic Review, 14(4): 621-636. https://www.researchgate.net/profile/Burcu Berke/publication/298214226 Doviz Piyasalarinin Etkinligi Turkiye icin Bir Analiz/links/56 ea6ebd08aec8bc0781a625/Doeviz-Piyasalarinin-Etkinligi-Tuerkiye-icin-Bir-Analiz.pdf. 
Bottero, M., Minoiu, C. Peydro, JL., Polo, A., Presbitero, A. \& Sette, E. (2019). Expansionary yet different: credit supply and real effects of negative interest rate policy. December 2019. CEPR Discussion Paper No. DP14233, pp.1-59. Available at SSRN: https://ssrn.com/abstract=3518571 or https://www.barcelonagse.eu/sites/default/files/working_paper_pdfs/1090.pdf

Bouoiyour, J., Selmi, R. \& Wohar, M.(2019). Bitcoin: competitor or complement to gold?. Economics Bulletin, 2019, 39 (1): pp.186-191. hal01994187, Post-Print, HAL, https://EconPapers.repec.org/RePEc:hal:journl:hal-01994187.

Burggraf, T. (2020). Bitcoin and global political uncertainty - Evidence from the U.S. election cycle. January 6, 2020, pp.1-12. Available at

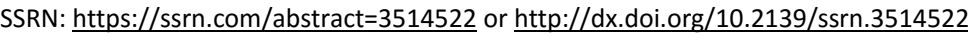

Canöz, í. (2020). The impact of US monetary growth on Bitcoin trading volume in the current economic uncertainty. In Handbook of Research on Decision-Making Techniques in Financial Marketing, pp. 493-509. IGI Global.

Cheong, C. (2019), "Cryptocurrencies vs global foreign exchange risk". Journal of Risk Finance, Vol. 20 No. 4, pp.330-351. DOI: https://doi.org/10.1108/JRF-11-2018-0178.

Chohan, U. W., (2018). Cryptocurrencies as asset-backed instruments: The Venezuelan Petro. February 7, 2018. pp.1-9. Available at SSRN: https://ssrn.com/abstract=3119606 or http://dx.doi.org/10.2139/ssrn.3119606

De Cnijf, C. (2019). Is gold still a safe haven? Doctoral dissertation, Ghent University, Master of Science in Business Administration, Supervisor: Prof. Dr. Koen Inghelbrecht, June 2019, pp.1-49. https://lib.ugent.be/fulltxt/RUG01/002/784/019/RUG01-002784019 2019 0001 AC.pdf

Dirican, C. \& Canöz, İ. (2017). The cointegration relationship between Bitcoin prices and major world stock indices: an analysis with ARDL Model approach. Journal of Economics Finance and Accounting, 4 (4): 377-392. DOI: 10.17261/Pressacademia.2017.748.

Engel, C. (1994). Can the Markov switching model forecast exchange rates?. Journal of international economics, 36(1-2): 151-165. https://www.ssc.wisc.edu/ cengel/PublishedPapers/JIEMarkov.pdf.

Erdoğdu, A. (2017). The most significant factors influencing the price of gold: an empirical analysis of the US market. Economics World, Sep.Oct. 2017, Vol. 5, No. 5, pp.399-406. DOI: 10.17265/2328-7144/2017.05.002.

Evans, O. (2019). The effects of US-China trade war and Trumponomics. MPRA Paper 93682, University Library of Munich, Germany, Forum Scientiae Oeconomia, 7(1): 47-55, https://mpra.ub.uni-muenchen.de/93682/1/MPRA_paper_93682.pdf

Evci, S., Şak, N. \& Karaağaç, G.A. (2016). Altın fiyatlarındaki değişimin Markov Rejim Değişim Modelleriyle incelenmesi. Business and Economics Research Journal, Volume 7, No 42016, pp. 67-77, ISSN: 1309-2448, DOI:10.20409/berj.2016422339

Garcia, R. (1998). Asymptotic Null Distribution of the Likelihood Ratio Test in Markov Switching Models. International Economic Review. pp.763-788. https://www.jstor.org/stable/2527399

Gözgör, G., Tiwari, A., Demir, E. \& Akron, S. (2019). The relationship between Bitcoin returns and trade policy uncertainty, Finance Research Letters, 29, issue C, p. 75-82, https://econpapers.repec.org/article/eeefinlet/v 3a29 3ay 3a2019 3ai 3ac 3ap 3a75-82.htm \& http://www.sciencedirect.com/science/article/pii/S1544612318308596

Günen, E. (2019). Türkiye'nin resmi kripto parası için hedef: 2020. Fintechtime.com Web Haber Sitesi, 09/11/2019, http://fintechtime.com/tr/2019/11/turkiyenin-resmi-kripto-parasi-icin-hedef-2020/

Hamilton, J. D. (1988). Rational-Expectations econometric analysis of changes in regime: an investigation of the term structure of interest rates. Journal of Economic Dynamics and Control. 12(2-3): 385-423. http://www.bu.edu/econ/files/2014/01/Hamilton-Interest-Rates.pdf

Hamilton, J. D. (1989). A new approach to the economic analysis of nonstationary time series and the business cycle. Econometrica: Journal of the Econometric Society, 57(2): 357-384. https://www.jstor.org/stable/1912559

Harihara Sudhan, R. I. \& Subramanian, S. (2018). How good is the Bitcoin as an alternative asset for hedging. International Journal of Pure and Applied Mathematics, Volume 119, No. 17, September 27, 2018, pp.497-508 ISSN: $1314-3395$. Available at SSRN: https://ssrn.com/abstract=3256074

Investing.com (Anonim). Haber ve veri sitesi. İlgili yatırım ürünleri veri sayfaları. https://tr.investing.com/. ET: 2019.

Jana, R. K., \& Das, D. (2020). Did Bitcoin act as an antidote to the Chinese equity market and booster to Altcoins during the Novel Coronavirus outbreak?, February 26, 2020, pp.1-28. Available at SSRN . https://ssrn.com/abstract=3544794

Khan, N.I. (2019). Global trade war and its impact on trade and growth: war between USA, China and EU. International Journal of Innovative Technology and Exploring Engineering (IJITEE), ISSN:2278-3075, Volume-8 Issue-8 June, 2019, pp.934-942. https://www.ijitee.org/wpcontent/uploads/papers/v8i8/G5629058719.pdf.

Kodama, O., Pichl, L., \& Kaizoji, T. (2017). Regime change and trend prediction for Bitcoin time series data. In CBU International Conference Proceedings, Vol. 5, pp. 384-388, September 2017. https://ojs.journals.cz/index.php/CBUIC/article/view/954.

Koutmos, D. (2019). Market risk and Bitcoin returns. Annals of Operations Research, pp.1-25. https://doi.org/10.1007/s10479-019-03255-6

Koy, A. (2017). Spot ve vadeli piyasa ilişkilerine Markov Rejim Değişim Modelleri yaklaşımı. Bankacılar Dergisi, Sayı 101, 24 Haziran 2017, ss.70-87. https://www.tbb.org.tr/Content/Upload/dergiler/dosya/76/tbb101.new.pdf 
Kula V., \& Baykut, E. (2017). BIST Banka Endeksi'nin (XBANK) volatilite yapısının Markov Rejim Değişimi GARCH Modeli (MSGARCH) ile analizi. Bankacılar Dergisi, Sayı 102, 2017, ss.89-110. https://www.tbb.org.tr/Content/Upload/dergiler/dosya/77/ Bankacilar Dergisi 102.Sayi.pdf.

Liu, T. \& Woo, W.T. (2018). Understanding the U.S.-China trade war. China Economic Journal, 11(3): 319-340, DOI: $10.1080 / 17538963.2018 .1516256$

Mita, M., Ito, K., Ohsawa, S., \& Tanaka, H. (2019). What is Stablecoin?: A Survey on Price Stabilization Mechanisms for Decentralized Payment Systems. arXiv preprint arXiv:1906.06037, 14 June 2019, pp.1-7. https://arxiv.org/ftp/arxiv/papers/1906/1906.06037.pdf

NYTimes.com. (2020). Asian Markets Seesaw, Bonds Rise as Coronavirus Fears Linger. The NYTimes Haber Web Sitesi, https://www.nytimes.com/2020/02/28/business/stock-market-today-coronavirus.html

Noland, M. (2018). US trade policy in the Trump administration. Asian Economic Policy Review, 13: 262-278. DOI:10.1111/aepr.12226

Palacıoğlu, T. (2018). ABD “Dünya”ya karşı!; Ticaret savaşları. ITO Bilgiyi Ticarileştirme ve Araştırma Vakfı, İstanbul Düşünce Akademisi, YAYıN NO: 2018, 11 Ağustos 2018, ss.1-12, https://www.istka.org.tr/media/131174/abd-dünyaya-karşı-ticaret-savaşları.pdf

Plakandaras, Bouri \& Gupta. (2019). Forecasting Bitcoin returns: is there a role for the U.S. - China trade war?. Working Papers 201980, University of Pretoria, Department of Economics, pp.1-17. http://www.up.ac.za/media/shared/61/WP/wp 2019 80.zp183111.pdf.

Rechard, K.L. (2019). Essays on monetary policy and Bitcoin financial economics. May 2019, pp.1-74. All Dissertations. 2367. https://tigerprints.clemson.edu/all_dissertations/2367

Steinbock, D. (2018). U.S.-China trade war and its global impacts, China Quarterly of International Strategic Studies, 2018, 04(04): 515-542. https://www.worldscientific.com/doi/pdf/10.1142/S2377740018500318.

Virk, N. (2019). Bitcoin and integration patterns in the Forex market. January 1, 2019, pp.1-15. Available at

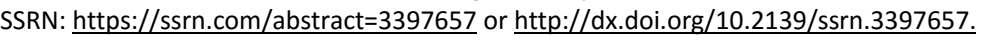

Wilner, D. P. (2018). LIBOR: London's interbank bridge is falling down. NY Business Law Journal, Winter 2018, Vol:22, No:2, pp. 64-79, https://static1.squarespace.com/static/5981d17d197aeacdba983f19/t/5c45dfef21c67cc78dc4b659/1548083186800/BusLawJournalWinter18.pdf\#page=66 


\section{Ek 1: Analizde Kullanılan Veri Seti}

\begin{tabular}{|c|c|c|c|c|c|c|c|c|c|c|c|}
\hline date & xag_usd & xau_usd & jpy_usd & chf_usd & btc_usd & date & xag_usd & xau_usd & jpy_usd & chf_usd & btc_usd \\
\hline 4.03 .2018 & 16,5240 & 1323,75 & 0,00946 & 1,0669 & 11454,00 & 2.12 .2018 & 14,2540 & 1223,42 & 0,00881 & 1,0027 & 4241,40 \\
\hline 11.03 .2018 & 16,6430 & 1324,31 & 0,00936 & 1,0522 & 8764,40 & 9.12 .2018 & 14,6390 & 1250,45 & 0,00887 & 1,0093 & 3506,00 \\
\hline 18.03 .2018 & 16,3720 & 1314,02 & 0,00944 & 1,0494 & 7832,00 & 16.12 .2018 & 14,5870 & 1237,24 & 0,00882 & 1,0040 & 3282,20 \\
\hline 25.03 .2018 & 16,6160 & 1348,51 & 0,00955 & 1,0558 & 8525,00 & 23.12.2018 & 14,7190 & 1258,53 & 0,00901 & 1,0057 & 4135,00 \\
\hline 1.04 .2018 & 16,3800 & 1326,12 & 0,00941 & 1,0487 & 6925,40 & 30.12 .2018 & 15,3910 & 1280,40 & 0,00907 & 1,0162 & 3893,80 \\
\hline 8.04 .2018 & 16,4530 & 1333,22 & 0,00935 & 1,0414 & 6892,60 & 6.01.2019 & 15,7370 & 1285,81 & 0,00921 & 1,0132 & 3911,00 \\
\hline 15.04 .2018 & 16,6510 & 1344,61 & 0,00931 & 1,0386 & 8003,00 & 13.01.2019 & 15,5980 & 1287,65 & 0,00921 & 1,0150 & 3702,00 \\
\hline 22.04 .2018 & 17,1460 & 1335,71 & 0,00929 & 1,0264 & 8917,60 & 20.01 .2019 & 15,3430 & 1281,65 & 0,00911 & 1,0053 & 3762,30 \\
\hline 29.04.2018 & 16,5320 & 1322,80 & 0,00917 & 1,0118 & 9340,30 & 27.01.2019 & 15,7450 & 1301,41 & 0,00913 & 1,0062 & 3630,70 \\
\hline 6.05 .2018 & 16,5570 & 1315,18 & 0,00916 & 0,9993 & 9859,60 & 3.02 .2019 & 15,9160 & 1318,09 & 0,00913 & 1,0047 & 3564,50 \\
\hline 13.05 .2018 & 16,6950 & 1319,16 & 0,00914 & 0,9987 & 8467,00 & 10.02 .2019 & 15,8160 & 1314,33 & 0,00911 & 0,9997 & 3718,30 \\
\hline 20.05 .2018 & 16,4180 & 1290,95 & 0,00903 & 1,0025 & 8230,90 & 17.02 .2019 & 15,7840 & 1321,40 & 0,00905 & 0,9937 & 3676,50 \\
\hline 27.05 .2018 & 16,5380 & 1298,74 & 0,00913 & 1,0102 & 7330,80 & 24.02.2019 & 15,8990 & 1329,22 & 0,00904 & 0,9991 & 4212,20 \\
\hline 3.06 .2018 & 16,4250 & 1293,51 & 0,00913 & 1,0108 & 7639,00 & 3.03.2019 & 15,2210 & 1293,57 & 0,00894 & 1,0011 & 3913,00 \\
\hline 10.06 .2018 & 16,7870 & 1299,61 & 0,00913 & 1,0136 & 7498,10 & 10.03 .2019 & 15,3170 & 1298,09 & 0,00901 & 0,9925 & 4017,30 \\
\hline 17.06.2018 & 16,5530 & 1279,55 & 0,00903 & 1,0037 & 6491,00 & 17.03.2019 & 15,3080 & 1302,12 & 0,00897 & 0,9977 & 4088,00 \\
\hline 24.06 .2018 & 16,5190 & 1272,41 & 0,00910 & 1,0115 & 6151,90 & 24.03.2019 & 15,4210 & 1313,90 & 0,00910 & 1,0043 & 4063,00 \\
\hline 1.07 .2018 & 16,1280 & 1253,89 & 0,00903 & 1,0091 & 6617,60 & 31.03 .2019 & 15,1270 & 1292,28 & 0,00901 & 1,0057 & 4165,10 \\
\hline 8.07 .2018 & 16,0440 & 1255,24 & 0,00905 & 1,0097 & 6761,80 & 7.04.2019 & 15,1180 & 1291,81 & 0,00895 & 0,9997 & 5091,10 \\
\hline 15.07 .2018 & 15,8350 & 1241,40 & 0,00890 & 0,9983 & 6250,00 & 14.04 .2019 & 14,9930 & 1291,22 & 0,00893 & 0,9974 & 5103,70 \\
\hline 22.07 .2018 & 15,5280 & 1231,30 & 0,00897 & 1,0071 & 7403,40 & 21.04 .2019 & 15,0050 & 1275,80 & 0,00894 & 0,9859 & 5340,10 \\
\hline 29.07.2018 & 15,4900 & 1222,96 & 0,00901 & 1,0052 & 8235,70 & 28.04.2019 & 15,0760 & 1286,76 & 0,00896 & 0,9808 & 5400,60 \\
\hline 5.08 .2018 & 15,4600 & 1213,71 & 0,00899 & 1,0051 & 7013,20 & 5.05 .2019 & 14,9460 & 1280,11 & 0,00904 & 0,9838 & 6098,20 \\
\hline 12.08 .2018 & 15,3300 & 1211,28 & 0,00901 & 1,0048 & 6234,70 & 12.05 .2019 & 14,7870 & 1286,65 & 0,00911 & 0,9881 & 7125,10 \\
\hline 19.08 .2018 & 14,7550 & 1183,78 & 0,00905 & 1,0041 & 6395,00 & 19.05 .2019 & 14,4150 & 1278,95 & 0,00908 & 0,9883 & 7260,10 \\
\hline 26.08 .2018 & 14,8650 & 1206,94 & 0,00899 & 1,0169 & 6732,80 & 26.05 .2019 & 14,5730 & 1284,91 & 0,00915 & 0,9988 & 8054,90 \\
\hline 2.09 .2018 & 14,5310 & 1200,34 & 0,00900 & 1,0320 & 7197,50 & 2.06 .2019 & 14,5970 & 1307,66 & 0,00923 & 0,9983 & 8546,90 \\
\hline 9.09 .2018 & 14,1900 & 1195,07 & 0,00901 & 1,0319 & 6184,90 & 9.06 .2019 & 14,9950 & 1336,91 & 0,00922 & 1,0127 & 7924,00 \\
\hline 16.09 .2018 & 14,0790 & 1193,23 & 0,00893 & 1,0330 & 6512,80 & 16.06 .2019 & 14,8770 & 1342,06 & 0,00922 & 1,0012 & 8852,80 \\
\hline 23.09 .2018 & 14,3200 & 1198,59 & 0,00888 & 1,0424 & 6723,10 & 23.06 .2019 & 15,3560 & 1400,46 & 0,00932 & 1,0232 & 10745,00 \\
\hline 30.09 .2018 & 14,6900 & 1192,21 & 0,00880 & 1,0198 & 6590,00 & 30.06 .2019 & 15,1930 & 1397,81 & 0,00924 & 1,0212 & 11973,00 \\
\hline 7.10 .2018 & 14,6760 & 1203,16 & 0,00879 & 1,0076 & 6595,20 & 7.07.2019 & 15,0130 & 1398,94 & 0,00922 & 1,0086 & 11276,00 \\
\hline 14.10 .2018 & 14,6170 & 1217,52 & 0,00892 & 1,0092 & 6326,00 & 14.07.2019 & 15,2260 & 1415,90 & 0,00926 & 1,0163 & 11324,00 \\
\hline 21.10 .2018 & 14,6550 & 1228,38 & 0,00889 & 1,0041 & 6582,90 & 21.07.2019 & 16,2450 & 1427,68 & 0,00928 & 1,0168 & 10741,00 \\
\hline 28.10 .2018 & 14,7200 & 1234,17 & 0,00894 & 1,0026 & 6498,40 & 28.07.2019 & 16,4090 & 1419,58 & 0,00920 & 1,0071 & 9463,10 \\
\hline 4.11 .2018 & 14,7520 & 1233,36 & 0,00884 & 0,9973 & 6389,20 & 4.08 .2019 & 16,2120 & 1440,01 & 0,00938 & 1,0174 & 10822,00 \\
\hline 11.11.2018 & 14,1420 & 1209,47 & 0,00879 & 0,9945 & 6431,00 & 11.08.2019 & 16,9790 & 1498,05 & 0,00947 & 1,0282 & 11308,00 \\
\hline 18.11.2018 & 14,4490 & 1222,44 & 0,00886 & 0,9982 & 5637,20 & 18.08 .2019 & 17,1390 & 1512,60 & 0,00941 & 1,0232 & 10230,00 \\
\hline 25.11 .2018 & 14,3220 & 1223,99 & 0,00885 & 1,0028 & 3934,90 & 25.08 .2019 & 17,5630 & 1542,99 & 0,00952 & 1,0277 & 10162,00 \\
\hline \multicolumn{6}{|c|}{ SAĞ YUKARIDAN DEVAM ETMEKTEDIR } & 1.09.2019 & 18,4220 & 1526,49 & 0,00943 & 1,0103 & 9623,90 \\
\hline
\end{tabular}

Kaynak: Investing.com (Anonim). Haber ve veri sitesi. İlgili yatırım ürünleri veri sayfaları. https://tr.investing.com/. ET: 2019. 